\title{
Impact of ARDS Etiology on the Failure of Noninvasive Ventilation and 28-Day Mortality: A Multicenter Prospective Observational Study
}

\section{Weiwei Shu}

The First Affiliated Hospital of Chongqing Medical University

\section{Shuliang Guo}

The First Affiliated Hospital of Chongqing Medical University

\section{Fuxun Yang}

Sichuan Province People's Hospital: Sichuan Academy of Medical Sciences and Sichuan People's

Hospital

\section{Bicui Liu}

The Bishan Hospital of Chongqing

\section{Zhongxing Zhang}

Affiliated Hospital of Chongqing Three Gorges Medical College

\section{Xiaoyi Liu}

The Central Hospital of Dazhou

\section{Baixu Chen}

Sichuan University West China Hospital

\section{Tao Huang}

The First Affiliated Hospital of Chongqing Medical University

\section{Liucun Li}

Second Xiangya Hospital

\section{Ke Wang}

The Second Affiliated Hospital of Chongqing Medical University

\section{Dehua He}

The Affiliated Hospital of Guizhou Medical University

\section{Qimin Chen}

The Affiliated Hospital of Guizhou Medical University

\section{Bilin Wei}

The First Affiliated Hospital, Sun Yat-sen Unniversity

\section{Lijuan Chen}

Sichuan Province People's Hospital: Sichuan Academy of Medical Sciences and Sichuan People's Hospital

\section{Manyun Tang}


The Chest Hospital of Xi'an

\section{Guodan Yuan}

Chongqing Public Health Medical Center

\section{Min Mao}

The First Affiliated Hospital of Chongqing Medical University

\section{ZhiJun Tang}

The People's Hospital of Nanchuan

\section{Fei Ding}

The Bishan Hospital of Chongqing

\section{Wenpin Ge}

Affiliated Hospital of Chongqing Three Gorges Medical College

\section{Xiaoli Han}

The First Affiliated Hospital of Chongqing Medical University

\section{Rui Zhang}

The First Affiliated Hospital of Chongqing Medical University

\section{Lei Jiang}

The First Affiliated Hospital of Chongqing Medical University

\section{Linfu Bai}

The First Affiliated Hospital of Chongqing Medical University

Jun Duan ( $\nabla$ duanjun412589@163.com )

the First Affiliated Hospital of Chongqing Medical University https://orcid.org/0000-0003-1685-0117

\section{Research}

Keywords: ARDS, noninvasive ventilation, oxygenation

Posted Date: February 12th, 2021

DOI: https://doi.org/10.21203/rs.3.rs-220238/v1

License: (c) (i) This work is licensed under a Creative Commons Attribution 4.0 International License. Read Full License 


\section{Abstract}

Background: The failure rate of noninvasive ventilation (NIV) remains high in patients with acute respiratory distress syndrome (ARDS). The etiology of ARDS may play an important role in NIV failure.

Methods: A multicenter prospective observational study was performed in 17 ICUs in China from September 2017 to December 2019. ARDS patients who used NIV as a first-line therapy were enrolled. The etiology of ARDS was recorded at study entry.

Results: A total of 306 patients were enrolled. Of the patients, 146 were classified as having pulmonary ARDS (ARDSp) and 160 were classified as having extrapulmonary ARDS (ARDSexp). NIV improved $\mathrm{PaO}_{2} / \mathrm{FiO}_{2}$ from initiation to $24 \mathrm{~h}$ of NIV in both groups. However, it improved more slowly in patients with ARDSp than in those with ARDSexp (interaction effect: $p<0.01$ ). ARDSp patients experienced more NIV failure $(55 \%$ vs. $28 \%$; $p<0.01)$ and higher 28 -day mortality ( $47 \%$ vs. $14 \% ; p<0.01)$. The multivariate Cox regression also showed that ARDSp was independently associated with NIV failure (hazard ratio [HR] = 2.81, 95\% confidence interval [Cl]: 1.89-4.18) and 28-day mortality ( $\mathrm{HR}=7.49,95 \% \mathrm{Cl}: 4.32-13.01)$. After propensity matching, 62 patients remained in each group. The baseline data were comparable between the two groups. ARDSp was still independently associated with NIV failure and 28-day mortality (HR = $2.62,95 \% \mathrm{Cl}: 1.49-4.61$; and $5.70,2.59-12.55$, respectively). Sensitivity analysis also confirmed these results.

Conclusions: Among ARDS patients who used NIV as a first-line therapy, ARDSp was associated with slower improvement in oxygenation, more NIV failure, and higher 28-day mortality than ARDSexp.

\section{Background}

Noninvasive ventilation (NIV) reduces the work of breathing, improves oxygenation, and relieves dyspnea in patients with acute respiratory failure [1]. Compared to standard oxygen therapy, NIV reduces the rate of intubation and the length of stay in the intensive care unit (ICU) [2-4]. Moreover, compared to invasive mechanical ventilation, NIV avoids intubation-associated lung injury, reduces ventilator-associated pneumonia, and preserves the ability to cough and communicate verbally $[5,6]$. Therefore, the use of NIV in cases of acute respiratory failure increases year after year $[7,8]$.

A large epidemiologic study of 50 countries showed that $15 \%$ of patients with acute respiratory distress syndrome (ARDS) use NIV as a first-line therapy [9]. However, the pooled NIV failure rate is $48 \%$ (range: $30-86 \%$ ) [10]. Among the ARDS population, mortality is $46 \%$ in patients who initially receive intubation for invasive mechanical ventilation; however, it increases to $69 \%$ in those who experience NIV failure [11]. As NIV failure is associated with increased mortality, identifying ARDS patients who respond well to NIV is important.

The etiologies of ARDS include pneumonia, aspiration, drowning, intra-abdominal infection, urinary infection, pancreatitis, and so on $[12,13]$. These causes can be classified as pulmonary ARDS (ARDSp) or 
extrapulmonary ARDS (ARDSexp). In one study, ARDSp patients required a longer duration of mechanical ventilation than ARDSexp patients [14]. Another study with a small sample size reported that ARDSp patients tended to have higher hospital mortality than ARDSexp patients ( $47.4 \%$ vs. $27.9 \%)$ [15]. Finally, physiological studies have shown that responses to lung recruitment and prone position differ between patients with ARDSp and ARDSexp [16, 17]. These differences can be explained by the different pathophysiological mechanisms of the two types of ARDS. Based on these data, we hypothesized that the response to NIV would differ in patients with ARDSp and ARDSexp.

\section{Methods}

This prospective observational study was performed in 17 ICUs in China from September 2017 to December 2019. We enrolled ARDS patients who used NIV as a first-line therapy. Exclusion criteria were as follows: previous use of NIV $>2 \mathrm{~h}$ before admission to participating centers, ventilation support from high-flow nasal cannula to NIV or from NIV to high-flow nasal cannula, NIV carried out within the $48 \mathrm{~h}$ after extubation, and transfer to another hospital during NIV. As we aimed to assess the impact of ARDS etiology on NIV failure, we also excluded patients with treatment limitation. The study protocol was approved by our ethics committee (No. 2016150). Informed consent was obtained from patients or their family members. ARDS was determined as follows: 1) the presence of acute hypoxemic respiratory failure with $\mathrm{PaO}_{2} / \mathrm{FiO}_{2}<300 \mathrm{mmHg} ; 2$ ) within 1 week of a clinical insult or the presence of new (within 7 days) or worsening respiratory symptoms; 3 ) bilateral opacities on computed tomography or chest X-ray not fully explained by effusions, lobar or lung collapse, or nodules; and 4) respiratory failure not fully explained by cardiac failure or fluid overload [18]. The etiology of ARDS was recorded by the attending physician.

The initiation of NIV was based on a protocol we published previously: respiratory rate $>25$ breaths $/ \mathrm{min}$, or clinical presentation of respiratory distress at rest (such as active contraction of the accessory inspiratory muscles or paradoxical abdominal motion), and $\mathrm{PaO}_{2}<60 \mathrm{mmHg}$ at room air or $\mathrm{PaO}_{2} / \mathrm{FiO}_{2}<$ $300 \mathrm{mmHg}$ with supplemental oxygen [19]. However, the use of NIV was at the attending physician's discretion. A face mask was the first choice for patients with acute respiratory failure, and the size was selected based on the patient's facial type. The straps of the mask were kept as tight as possible while remaining comfortable for the patient. The parameters of the ventilator were adjusted as follows. The initial positive end-expiratory pressure (PEEP) was $4 \mathrm{~cm} \mathrm{H}_{2} \mathrm{O}$ and was increased gradually to avoid alveolar collapse. The initial inspiratory positive airway pressure (IPAP) was $8 \mathrm{cmH}_{2} \mathrm{O}$ (above zero) and was increased gradually to reduce the work of breathing. Usually PEEP was maintained at $6-8 \mathrm{cmH}_{2} \mathrm{O}$ and IPAP was maintained at $12-16 \mathrm{cmH}_{2} \mathrm{O}$. The fraction of inspiration oxygen $\left(\mathrm{FiO}_{2}\right)$ was set to maintain $\mathrm{SpO}_{2}$ around $95 \%$.

Liberation from NIV was considered if the respiratory failure was reversed. The reversal of respiratory failure was defined according to previously published criteria: $\mathrm{PaO}_{2} / \mathrm{FiO}_{2}>300 \mathrm{mmHg}$, respiratory rate < 25 breaths/min, and no clinical symptoms indicating respiratory distress [19]. However, if respiratory 
failure deteriorated progressively and required intubation, intubation for invasive mechanical ventilation was performed. Major criteria for intubation were loss of consciousness (such as a sudden change from being awake to being unconscious), respiratory or cardiac arrest, the development of conditions necessitating intubation to protect the airway (coma or seizure disorders) or to manage copious tracheal secretions, heart rate $<50$ beats/min with loss of alertness, and hemodynamic instability without response to fluids and vasoactive agents. Minor criteria were respiratory rate $>35$ breaths $/ \mathrm{min}$, failure to maintain $\mathrm{PaO}_{2} / \mathrm{FiO}_{2}$ above $150 \mathrm{mmHg}$, acidosis with $\mathrm{pH}<7.35$, inability to correct dyspnea, and lack of improvement in respiratory muscle fatigue. Intubation was recommended if the patient reached one major criterion or more than two minor criteria. NIV failure was defined as requiring intubation [19].

A predefined case report form was used to collect data during the study period. We recorded age, sex, underlying disease, presence of septic shock, organ dysfunction, and etiology of ARDS. Organ dysfunction was assessed with the sequential organ failure assessment (SOFA) score [20]. Septic shock was diagnosed according to the Third International Consensus Definitions for Sepsis and Septic Shock [21]. Data were collected when NIV was performed. ARDS resulting from pneumonia, pulmonary contusion or drowning was classified as ARDSp; that resulting from pancreatitis, intra-abdominal infection, urinary infection, soft tissue infection, non-pulmonary trauma, or other non-pulmonary disease was classified as ARDSexp [12, 13]. All patients were followed to discharge or 28 days.

\section{Statistical analysis}

We used SPSS (version 25.0) to analyze the data in this study. Missing data were present in $4.6 \%$ of cases and multiple imputations were performed. Continuous variables are reported as means and standard deviations or medians and interquartile ranges when appropriate. Normally distributed continuous variables were analyzed by unpaired Student's $t$ test, and non-normally distributed continuous variables were analyzed by Wilcoxon rank sum test. Proportions are reported as frequencies and percentages and compared with the chi-square test or Fisher's exact test. Cox regression was used to identify independent risk factors associated with NIV failure or 28-day mortality. Differences in $\mathrm{PaO}_{2} / \mathrm{FiO}_{2}$ from initiation to $24 \mathrm{~h}$ of NIV between groups were analyzed by two-way repeated measures analysis of variance.

Propensity score matching was used to evaluate possible effects of treatment (ARDSp vs. ARDSexp) on NIV failure and 28-day mortality. We matched patients with similar propensity scores at a 1:1 ratio, using the nearest neighbor method, no replacement, and a caliper width of 0.05 . The matched variables included age, sex, non-pulmonary SOFA score, presence of septic shock, underlying disease (chronic heart disease or chronic respiratory disease), severity of ARDS, vital signs collected before NIV (heart rate, respiratory rate, mean arterial blood pressure, $\mathrm{pH}, \mathrm{PaCO}_{2}$, and $\mathrm{PaO}_{2} / \mathrm{FiO}_{2}$ ), tidal volume at $1-2 \mathrm{~h}$ of NIV, and PEEP at 1-2 $\mathrm{h}$ of NIV. We analyzed the cumulative 28-day probability of survival in the overall and propensity-matched cohorts by creating Kaplan-Meier curves, and the difference between the groups was analyzed by log-rank test. Sensitivity analysis in patients with different conditions was used to determine 
the effect of ARDS etiology on the failure of NIV and 28-day mortality. A p value less than 0.05 was considered statistically significant.

\section{Results}

A total of 306 ARDS patients were enrolled in this study (Fig. 1). The baseline data are summarized in Table 1. Based on etiology, 146 (48\%) patients were classified into the ARDSp group, and 160 (52\%) patients were classified into the ARDSexp group. ARDSp patients were more likely to be male $(69 \%$ vs. $56 \% ; \mathrm{p}=0.02)$, and had a lower $\mathrm{PaO}_{2} / \mathrm{FiO}_{2}$ at study entry $(137 \pm 44$ vs. $170 \pm 48 \mathrm{mmHg} ; \mathrm{p}<0.01)$ than ARDSexp patients (Table 1). They also had a lower non-pulmonary SOFA score (median: 1 vs. $2 ; p<0.01$ ), a lower proportion of septic shock ( $9 \%$ vs. $18 \%$; $p=0.03)$, and a lower heart rate $(111 \pm 23$ vs. $126 \pm 22$ beats/min; $p<0.01)$. After propensity matching, we enrolled 62 patients in each group. The variables at baseline were comparable between the two groups. 
Table 1

Baseline data between patients with pulmonary and extrapulmonary ARDS

\begin{tabular}{|c|c|c|c|c|c|c|}
\hline & \multicolumn{3}{|c|}{ Overall cohort } & \multicolumn{3}{|c|}{$\begin{array}{l}\text { Propensity-matched } \\
\text { cohort }\end{array}$} \\
\hline & ARDSp & ARDSexp & $\mathrm{p}$ & ARDSp & ARDSexp & $\mathrm{p}$ \\
\hline & $N=146$ & $N=160$ & & $N=62$ & $N=62$ & \\
\hline Age, years & $55 \pm 16$ & $52 \pm 16$ & 0.13 & $56 \pm 17$ & $55 \pm 18$ & 0.78 \\
\hline Male & $101(69 \%)$ & $89(56 \%)$ & 0.02 & $40(65 \%)$ & $40(65 \%)$ & $\overrightarrow{0.99}$ \\
\hline SOFA score & $4(3-6)$ & $5(4-7)$ & <. 01 & $4(4-7)$ & $5(3-7)$ & 0.72 \\
\hline $\begin{array}{l}\text { Non-pulmonary SOFA } \\
\text { score }\end{array}$ & $1(0-2)$ & $2(1-4)$ & $\begin{array}{l}< \\
0.01\end{array}$ & $1(1-4)$ & $2(1-4)$ & 0.53 \\
\hline Septic shock & $13(9 \%)$ & $28(18 \%)$ & 0.03 & $6(10 \%)$ & $7(11 \%)$ & $\begin{array}{l}> \\
0.99\end{array}$ \\
\hline Chronic heart disease & $13(9 \%)$ & $7(4 \%)$ & 0.16 & $3(5 \%)$ & $4(7 \%)$ & $\overrightarrow{0} .99$ \\
\hline $\begin{array}{l}\text { Chronic respiratory } \\
\text { disease }\end{array}$ & $9(6 \%)$ & $3(2 \%)$ & 0.08 & $3(5 \%)$ & $3(5 \%)$ & $\begin{array}{l}> \\
0.99\end{array}$ \\
\hline \multicolumn{7}{|l|}{ Etiology of ARDS } \\
\hline Pneumonia & $142(97 \%)$ & - & & 59 (95\%) & - & \\
\hline Pulmonary contusion & $3(2 \%)$ & - & & $2(3 \%)$ & - & \\
\hline Drowning & $1(1 \%)$ & - & & $1(2 \%)$ & - & \\
\hline Pancreatitis & - & $100(63 \%)$ & & - & $38(61 \%)$ & \\
\hline Intra-abdominal infection & - & $23(14 \%)$ & & - & $9(15 \%)$ & \\
\hline Urinary infection & - & $11(7 \%)$ & & - & $3(5 \%)$ & \\
\hline Trauma & - & $5(3 \%)$ & & - & $4(7 \%)$ & \\
\hline $\begin{array}{l}\text { Skin or soft tissue } \\
\text { infection }\end{array}$ & - & $4(3 \%)$ & & - & $3(5 \%)$ & \\
\hline Others & - & $17(11 \%)$ & & - & $5(8 \%)$ & \\
\hline
\end{tabular}

NIV = noninvasive ventilation, ARDS = acute respiratory distress syndrome, ARDSp $=$ pulmonary ARDS, ARDSexp = extrapulmonary ARDS, SOFA = sequential organ failure assessment, MAP = mean arterial pressure, $\mathrm{PEEP}=$ positive end expiratory pressure 


\begin{tabular}{|c|c|c|c|c|c|c|}
\hline \multirow[b]{2}{*}{ Heart rate, bpm } & \multicolumn{3}{|c|}{ Overall cohort } & \multicolumn{3}{|c|}{$\begin{array}{l}\text { Propensity-matched } \\
\text { cohort }\end{array}$} \\
\hline & $111 \pm 23$ & $126 \pm 22$ & $\begin{array}{l}< \\
0.01\end{array}$ & $119 \pm 22$ & $119 \pm 20$ & 0.83 \\
\hline Respiratory rate, bpm & $32 \pm 8$ & $32 \pm 8$ & 0.71 & $32 \pm 8$ & $32 \pm 7$ & 0.83 \\
\hline MAP, mmHg & $94 \pm 15$ & $96 \pm 18$ & 0.24 & $96 \pm 18$ & $95 \pm 17$ & 0.73 \\
\hline $\mathrm{pH}$ & $\begin{array}{l}7.44 \pm \\
0.08\end{array}$ & $\begin{array}{l}7.42 \pm \\
0.09\end{array}$ & $\begin{array}{l}<.01 \\
0.01\end{array}$ & $7.43 \pm 0.10$ & $7.43 \pm 0.08$ & 0.82 \\
\hline $\mathrm{PaCO}_{2}, \mathrm{mmHg}$ & $32 \pm 7$ & $32 \pm 7$ & 0.78 & $32 \pm 8$ & $32 \pm 7$ & 0.89 \\
\hline $\mathrm{PaO}_{2} / \mathrm{FiO}_{2}, \mathrm{mmHg}$ & $137 \pm 44$ & $170 \pm 48$ & $\begin{array}{l}< \\
0.01\end{array}$ & $153 \pm 46$ & $160 \pm 46$ & 0.38 \\
\hline \multicolumn{7}{|l|}{ ARDS severity } \\
\hline Mild & $18(12 \%)$ & $34(21 \%)$ & \multirow{3}{*}{$\begin{array}{l}< \\
0.01\end{array}$} & 12 (19\%) & $12(19 \%)$ & \multirow[t]{3}{*}{0.41} \\
\hline Moderate & 98 (67\%) & 119 (74\%) & & $43(69 \%)$ & 47 (76\%) & \\
\hline Severe & $20(21 \%)$ & $7(4 \%)$ & & $7(11 \%)$ & $3(5 \%)$ & \\
\hline \multicolumn{7}{|l|}{ Ventilator parameters } \\
\hline $\mathrm{V}_{\mathrm{T}}$ at $1-2 \mathrm{~h}$ of $\mathrm{NIV}, \mathrm{mL}$ & $532 \pm 181$ & $495 \pm 174$ & 0.06 & $525 \pm 199$ & $525 \pm 181$ & 0.98 \\
\hline PEEP at $1-2 \mathrm{~h}$ of NIV & $6(5-7)$ & $6(6-8)$ & $<.01$ & $6(5-8)$ & $6(6-7)$ & 0.99 \\
\hline $\mathrm{V}_{\mathrm{T}}$ at $12 \mathrm{~h}$ of $\mathrm{NIV}, \mathrm{mL}$ & $507 \pm 160$ & $465 \pm 155$ & 0.04 & $487 \pm 142$ & $491 \pm 162$ & 0.91 \\
\hline PEEP at $12 \mathrm{~h}$ of NIV & $6(5-8)$ & $6(6-8)$ & 0.03 & $6(5-8)$ & $6(6-8)$ & 0.81 \\
\hline $\mathrm{V}_{\mathrm{T}}$ at $24 \mathrm{~h}$ of $\mathrm{NIV}, \mathrm{mL}$ & $497 \pm 192$ & $465 \pm 147$ & 0.17 & $470 \pm 145$ & $509 \pm 166$ & 0.28 \\
\hline PEEP at $24 \mathrm{~h}$ of NIV & $6(5-8)$ & $6(6-8)$ & 0.16 & $7(5-8)$ & $6(6-8)$ & 0.55 \\
\hline
\end{tabular}

NIV improved $\mathrm{PaO}_{2} / \mathrm{FiO}_{2}$ both ARDSp and ARDSexp patients (Fig. 2). However, it improved more slowly in patients with ARDSp than in those with ARDSexp (interaction effect: $p<0.01$ ). And ARDSp patients experienced more NIV failure ( $52 \%$ vs. $28 \%$; $<0.01)$ and higher 28 -day mortality $(47 \%$ vs. $14 \% ; p<0.01$; Fig. 3). Similar results were confirmed in the propensity-matched cohort (NIV failure: $58 \%$ vs. $31 \%$; 28 -day mortality: $44 \%$ vs. $15 \%)$.

In the overall cohort, ARDSp was independently associated with NIV failure (hazard ratio $[H R]=2.81,95 \%$ confidence interval [Cl]: 1.89-4.18) and 28-day mortality (HR=7.49, 95\% Cl: 4.32-13.01; Table 2). In 
propensity-matched cohort, ARDSp was still independently associated with NIV failure and 28-day mortality ( $\mathrm{HR}=2.62,95 \% \mathrm{Cl}: 1.49-4.61$ and $5.70,2.59-12.55$, respectively). Sensitivity analysis was summarized in Fig. 4. ARDSp was also associated with NIV failure and 28-day mortality in different subgroups.

Table 2

Multivariate Cox regression analysis to determine the factor associated with NIV failure and 28-day mortality

\begin{tabular}{|c|c|c|c|c|}
\hline & $\begin{array}{l}\text { Overall cohort } \\
\text { HR (95\%Cl) }\end{array}$ & p & $\begin{array}{l}\text { Propensity-matched cohort } \\
\text { HR }(95 \% \mathrm{Cl})\end{array}$ & p \\
\hline \multicolumn{5}{|l|}{ NIV failure } \\
\hline ARDSp & $2.81(1.89-4.18)$ & $<0.01$ & $2.62(1.49-4.61)$ & $<0.01$ \\
\hline $\mathrm{V}_{\mathrm{T}}, \mathrm{mL}$ & $1.001(1.001-1.002)$ & $<0.01$ & $1.002(1.002-1.003)$ & $<0.01$ \\
\hline Non-pulmonary SOFA & $1.20(1.12-1.28)$ & $<0.01$ & $1.14(1.03-1.27)$ & 0.01 \\
\hline Respiratory rate, bpm & $1.04(1.01-1.06)$ & $<0.01$ & - & - \\
\hline Age, years & $1.01(1.00-1.03)$ & 0.02 & - & - \\
\hline \multicolumn{5}{|l|}{ 28-day mortality } \\
\hline ARDSp & $7.49(4.32-13.01)$ & $<0.01$ & $5.70(2.59-12.55)$ & $<0.01$ \\
\hline Age, years & $1.02(1.01-1.03)$ & $<0.01$ & $1.03(1.01-1.05)$ & 0.02 \\
\hline Non-pulmonary SOFA & $1.26(1.16-1.36)$ & $<0.01$ & $1.40(1.23-1.60)$ & $<0.01$ \\
\hline $\mathrm{V}_{\mathrm{T}}, \mathrm{mL}$ & $1.001(1.000-1.002)$ & 0.03 & - & - \\
\hline \multicolumn{5}{|c|}{$\begin{array}{l}\text { We entered sex, age, septic shock, chronic heart disease, chronic respiratory disease, non-pulmonary } \\
\text { SOFA score, ARDS severity, respiratory rate before NIV, heart rate before NIV, arterial blood gas tests } \\
\left.\text { before NIV ( } \mathrm{pH}, \mathrm{PaCO}_{2} \text { and } \mathrm{PaO}_{2} / \mathrm{FiO}_{2}\right) \text {, tidal volume at } 1-2 \mathrm{~h} \text { of NIV, and PEEP at } 1-2 \mathrm{~h} \text { of NIV into } \\
\text { the Cox regression model. }\end{array}$} \\
\hline \multicolumn{5}{|c|}{$\begin{array}{l}\mathrm{HR}=\text { hazard ratio, } \mathrm{Cl}=\text { confidence interval, NIV = noninvasive ventilation, } \mathrm{ARDS}=\text { acute respiratory } \\
\text { distress syndrome, ARDSp = pulmonary ARDS, SOFA = sequential organ failure assessment, PEEP = } \\
\text { positive end expiratory pressure }\end{array}$} \\
\hline
\end{tabular}

\section{Discussion}

This multicenter study shows that $\mathrm{PaO}_{2} / \mathrm{FiO}_{2}$ from initiation to $24 \mathrm{~h}$ of $\mathrm{NIV}$ improved slower in patients with ARDSp than in those with ARDSexp. More NIV failure and higher 28-day mortality were observed in ARDSp patients. And ARDSp was associated with NIV failure and 28-day mortality regardless of whether it was in overall cohort, propensity-matched cohort, or other subgroups. 
Our study shows that ARDSexp patients respond better to NIV than ARDSp patients. The different pathophysiological mechanisms of the two types of ARDS contribute greatly to the different effects of NIV among patients. The main etiologies of ARDSp are pneumonia, aspiration, and drowning. These factors cause injury to the pulmonary epithelium and direct insult to the alveolus [12]. This direct insult is mainly represented by alveolar filling by edema, fibrin, collagen, neutrophilic aggregates, and/or blood. In contrast, the predominant etiologies of ARDSexp are non-pulmonary sepsis, pancreatitis, and trauma. These factors cause injury to pulmonary endothelial cells and lead to microvascular congestion and interstitial edema, with a relative sparing of the intra-alveolar spaces. In addition, consolidation on chest CT scan is greater and response to lung recruitment maneuver worse in ARDSp patients than in ARDSexp patients $[22,23]$. These pathophysiological mechanisms can explain the better response to NIV in ARDSexp patients than in ARDSp patients.

Among NIV patients with de novo acute respiratory failure, delayed intubation is associated with increased hospital mortality [24]. As ARDS accounts for a large proportion of de novo acute respiratory failure, early identification of NIV failure in ARDS patients has the potential to reduce mortality. In our study, we innovatively explored the impact of ARDS etiology on NIV failure and found that ARDSp patients experience more NIV failure and higher 28-day mortality than ARDSexp patients. Therefore, this study provides new insight for clinical staff managing NIV in ARDS patients. More attention should be paid to ARDSp patients to avoid delayed intubation.

Organ dysfunction is associated with NIV failure $[19,25]$. Higher SOFA scores are also associated with more NIV failure. However, the lung is one of six organs assessed for the SOFA score. The pulmonary SOFA score is collinear with $\mathrm{PaO}_{2} / \mathrm{FiO}_{2}$. Thus, we used the non-pulmonary SOFA score to assess the risk for NIV failure and found it was associated with NIV failure. In addition, we also found the tidal volume was associated with NIV failure, which was similar with previous studies [26, 27]. Therefore, assessment of NIV failure in ARDSexp patients should be considered other risk factors (e.g. non-pulmonary SOFA score and tidal volume).

This study was limited by its methodology. Although we predefined the criteria for intubation, the decision to intubate was made by the attending physicians. This may have led to bias in the incidence of NIV failure. Second, the expired tidal volume of predicted body weight is associated with NIV failure [26, 27]. However, the height was not recorded in our study. We were unable to calculate the tidal volume of predicted body weight. This may diminish the association between NIV failure and tidal volume. Third, missing data were present in $4.6 \%$ of cases. However, we used multiple imputations to deal with this problem, which may partly improve the accuracy of the results.

\section{Conclusions}

Nearly half of ARDS patients in this study who received NIV as a first-line therapy had an ARDS etiology that was pulmonary in origin. From initiation to $24 \mathrm{~h}$ of $\mathrm{NIV}, \mathrm{PaO}_{2} / \mathrm{FiO}_{2}$ improved more slowly in ARDSp 
patients than in ARDSexp patients. ARDSp patients experienced more NIV failure and higher 28-day mortality.

\section{Abbreviations}

NIV = noninvasive ventilation

ARDS $=$ acute respiratory distress syndrome

ARDSp $=$ pulmonary ARDS

ARDSexp $=$ extra-pulmonary ARDS

SOFA = sequential organ failure assessment

MAP = mean arterial pressure

PEEP = positive end expiratory pressure

$\mathrm{HR}=$ hazard ratio

$\mathrm{Cl}=$ confidence interval

HFNC $=$ high-flow nasal cannula

\section{Declarations}

Consent for publication

All authors have reviewed and approved the manuscript for publication.

Availability of data and material

The datasets analyzed during the current study available from the corresponding author on reasonable request.

Ethical approval and consent to participate

The Institutional Review Board of the First Affiliated Hospital of Chongqing Medical University approved the study (No. 2016150). Informed consent was obtained from patients or their family members.

Competing interests

We declare that we have no competing interests.

Funding 
This study was supported by Pei Yu Ji Jin of the First Affiliated Hospital of Chongqing Medical University (PYJJ201707).

Authors' contributions

WS, SG, FY, BL, ZZ, XL and JD participated in study conception, study design, and study supervision. WS, $\mathrm{BL}, \mathrm{ZZ}$ and JD participated in data analysis and data interpretation. WS, SG, FY, ZZ, XL, BC, TH, LL, KW, $\mathrm{DH}, \mathrm{QC}, \mathrm{BW}, \mathrm{LC}, \mathrm{MT}, \mathrm{GY}, \mathrm{MM}, \mathrm{ZT}, \mathrm{FD}, \mathrm{WG}, \mathrm{XH}, \mathrm{RZ}, \mathrm{LJ}, \mathrm{LB}$ and JD participated in patient recruitment. All authors revised the manuscript and approved the final manuscript.

Acknowledgements

Authors thank all health care workers for their contribution to patient management.

\section{References}

1. L'Her E, Deye N, Lellouche F, et al. Physiologic effects of noninvasive ventilation during acute lung injury. Am J Respir Crit Care Med. 2005;172:1112-8.

2. Luo J, Wang MY, Zhu H, et al. Can non-invasive positive pressure ventilation prevent endotracheal intubation in acute lung injury/acute respiratory distress syndrome? A meta-analysis. Respirology. 2014;19:1149-57.

3. Xu X, Yuan B, Liang Q, et al. Noninvasive ventilation for acute lung injury a meta-analysis of randomized controlled trials. Heart Lung. 2016;45:249-57.

4. Ferreyro BL, Angriman F, Munshi L, et al. Association of Noninvasive Oxygenation Strategies With AllCause Mortality in Adults With Acute Hypoxemic Respiratory Failure: A Systematic Review and Metaanalysis. JAMA. 2020;324:57-67.

5. Papazian L, Klompas M, Luyt CE. Ventilator-associated pneumonia in adults: a narrative review. Intensive Care Med. 2020;46:888-906.

6. Jaber S, Bellani G, Blanch L, et al. The intensive care medicine research agenda for airways, invasive and noninvasive mechanical ventilation. Intensive Care Med. 2017;43:1352-65.

7. Walkey AJ, Wiener RS. Use of noninvasive ventilation in patients with acute respiratory failure, 20002009: a population-based study. Ann Am Thorac Soc. 2013;10:10-7.

8. Demoule A, Chevret $S$, Carlucci $A$, et al. Changing use of noninvasive ventilation in critically ill patients: trends over 15 years in francophone countries. Intensive Care Med. 2016;42:82-92.

9. Bellani G, Laffey JG, Pham T, et al. Noninvasive Ventilation of Patients with Acute Respiratory Distress Syndrome. Insights from the LUNG SAFE Study. Am J Respir Crit Care Med. 2017;195:6777.

10. Agarwal R, Aggarwal AN, Gupta D. Role of noninvasive ventilation in acute lung injury/acute respiratory distress syndrome: a proportion meta-analysis. Respir Care. 2010;55:1653-60. 
11. Chawla R, Mansuriya J, Modi N, et al. Acute respiratory distress syndrome: Predictors of noninvasive ventilation failure and intensive care unit mortality in clinical practice. J Crit Care. 2016;31:26-30.

12. Rocco PR, Zin WA. Pulmonary and extrapulmonary acute respiratory distress syndrome: are they different? Curr Opin Crit Care. 2005;11:10-7.

13. Huang X, Zhang R, Fan G, et al. Incidence and outcomes of acute respiratory distress syndrome in intensive care units of mainland China: a multicentre prospective longitudinal study. Crit Care. 2020;24:515.

14. Kim SJ, Oh BJ, Lee JS, et al. Recovery from lung injury in survivors of acute respiratory distress syndrome: difference between pulmonary and extrapulmonary subtypes. Intensive Care Med. 2004;30:1960-3.

15. Suntharalingam G, Regan K, Keogh BF, et al. Influence of direct and indirect etiology on acute outcome and 6-month functional recovery in acute respiratory distress syndrome. Crit Care Med. 2001;29:562-6.

16. Tugrul S, Akinci O, Ozcan PE, et al. Effects of sustained inflation and postinflation positive endexpiratory pressure in acute respiratory distress syndrome: focusing on pulmonary and extrapulmonary forms. Crit Care Med. 2003;31:738-44.

17. Lim CM, Kim EK, Lee JS, et al. Comparison of the response to the prone position between pulmonary and extrapulmonary acute respiratory distress syndrome. Intensive Care Med. 2001;27:477-85.

18. Ranieri VM, Rubenfeld GD, Thompson BT, et al. Acute respiratory distress syndrome: the Berlin Definition. JAMA. 2012;307:2526-33.

19. Duan J, Chen L, Liang G, et al. Noninvasive ventilation failure in patients with hypoxemic respiratory failure: the role of sepsis and septic shock. Ther Adv Respir Dis. 2019;13:1753466619888124.

20. Vincent JL, de Mendonça A, Cantraine F, et al. Use of the SOFA score to assess the incidence of organ dysfunction/failure in intensive care units: results of a multicenter, prospective study. Working group on "sepsis-related problems" of the European Society of Intensive Care Medicine. Crit Care Med. 1998;26:1793-800.

21. Singer M, Deutschman CS, Seymour CW, et al. The Third International Consensus Definitions for Sepsis and Septic Shock (Sepsis-3). JAMA. 2016;315:801-10.

22. Goodman LR, Fumagalli R, Tagliabue $P$, et al. Adult respiratory distress syndrome due to pulmonary and extrapulmonary causes: CT, clinical, and functional correlations. Radiology. 1999;213:545-52.

23. Lim CM, Jung $\mathrm{H}$, Koh $\mathrm{Y}$, et al. Effect of alveolar recruitment maneuver in early acute respiratory distress syndrome according to antiderecruitment strategy, etiological category of diffuse lung injury, and body position of the patient. Crit Care Med. 2003;31:411-8.

24. Carrillo A, Gonzalez-Diaz G, Ferrer M, et al. Non-invasive ventilation in community-acquired pneumonia and severe acute respiratory failure. Intensive Care Med. 2012;38:458-66.

25. Rana S, Jenad H, Gay PC, et al. Failure of non-invasive ventilation in patients with acute lung injury: observational cohort study. Crit Care. 2006;10:R79. 
26. Carteaux G, Millán-Guilarte T, De Prost N, et al. Failure of Noninvasive Ventilation for De Novo Acute Hypoxemic Respiratory Failure: Role of Tidal Volume. Crit Care Med. 2016;44:282-90.

27. Frat JP, Ragot S, Coudroy R, et al. Predictors of Intubation in Patients With Acute Hypoxemic Respiratory Failure Treated With a Noninvasive Oxygenation Strategy. Crit Care Med. 2018;46:20815.

Figures 


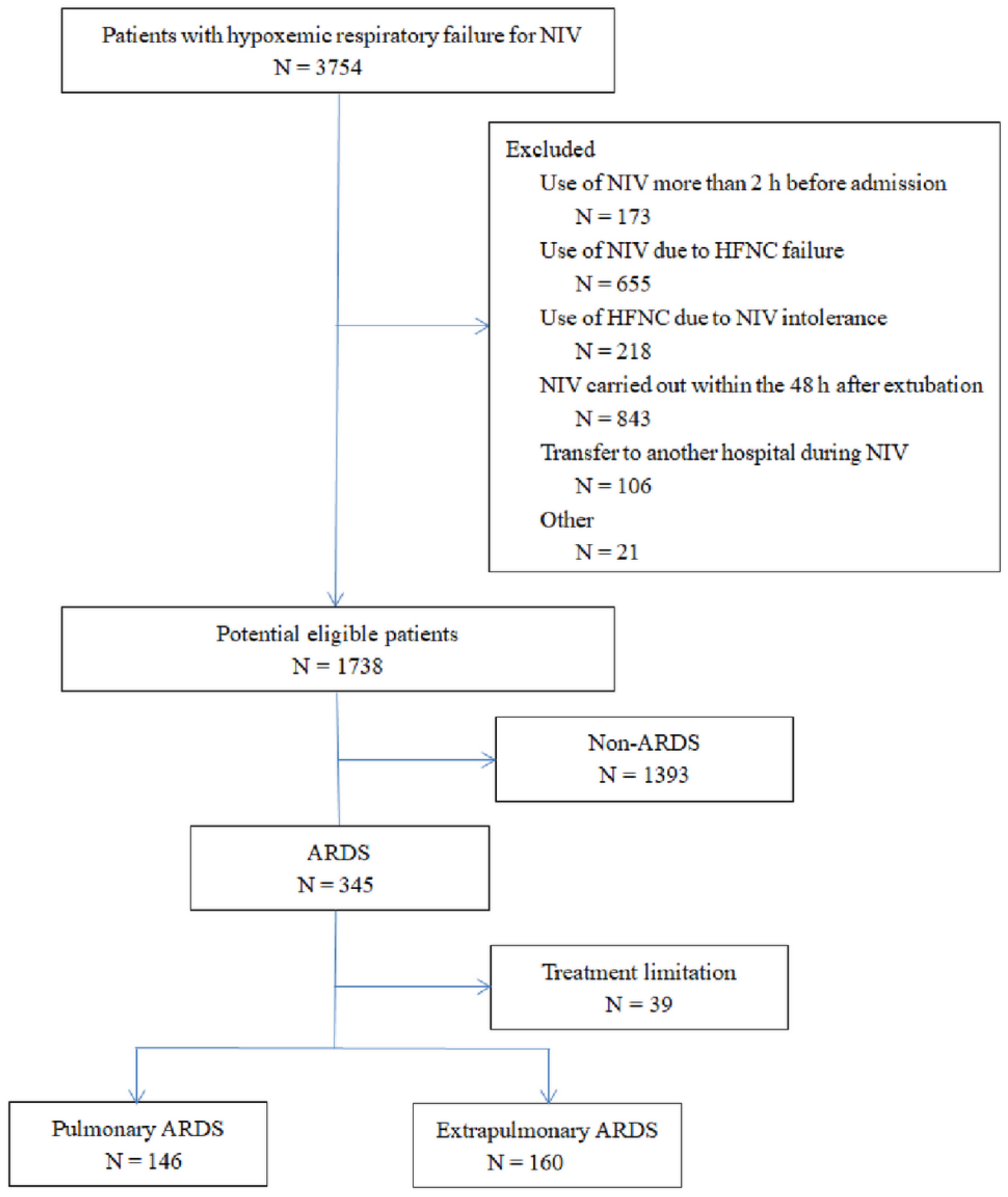

\section{Figure 1}

Flow of patient screening and enrollment 


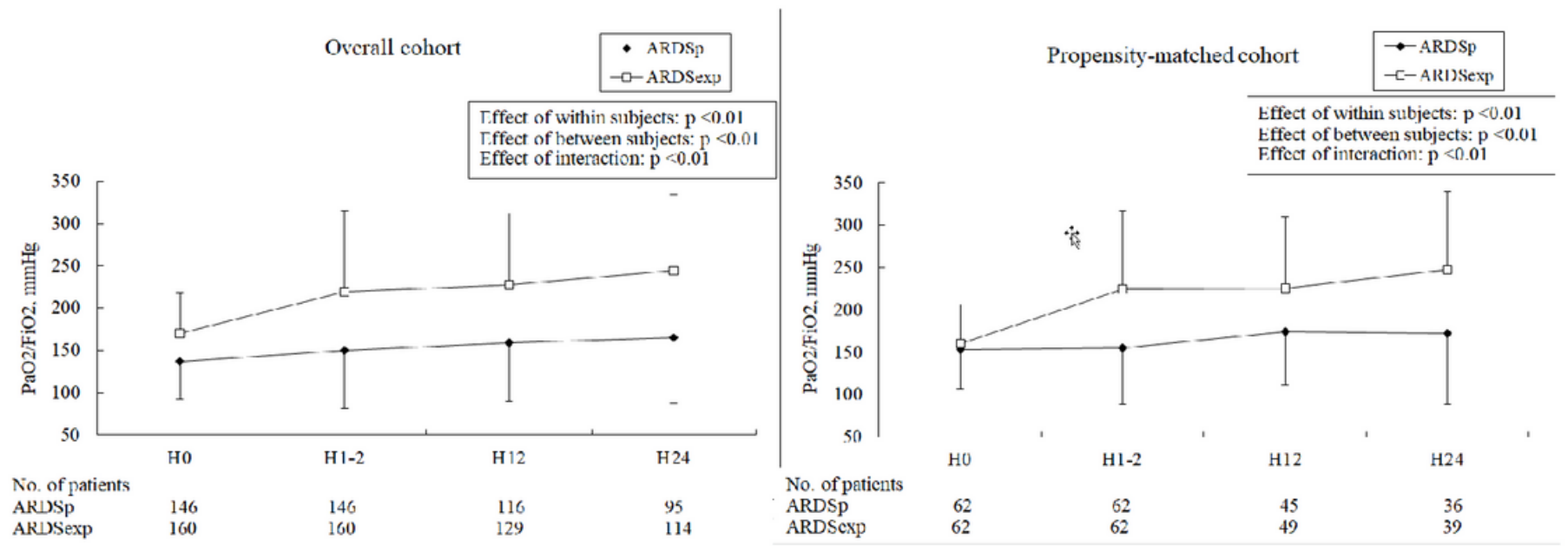

Figure 2

$\mathrm{PaO2} / \mathrm{FiO} 2$ from initiation to $24 \mathrm{~h}$ of NIV in patients with pulmonary ARDS (ARDSp) and extrapulmonary ARDS (ARDSexp) 


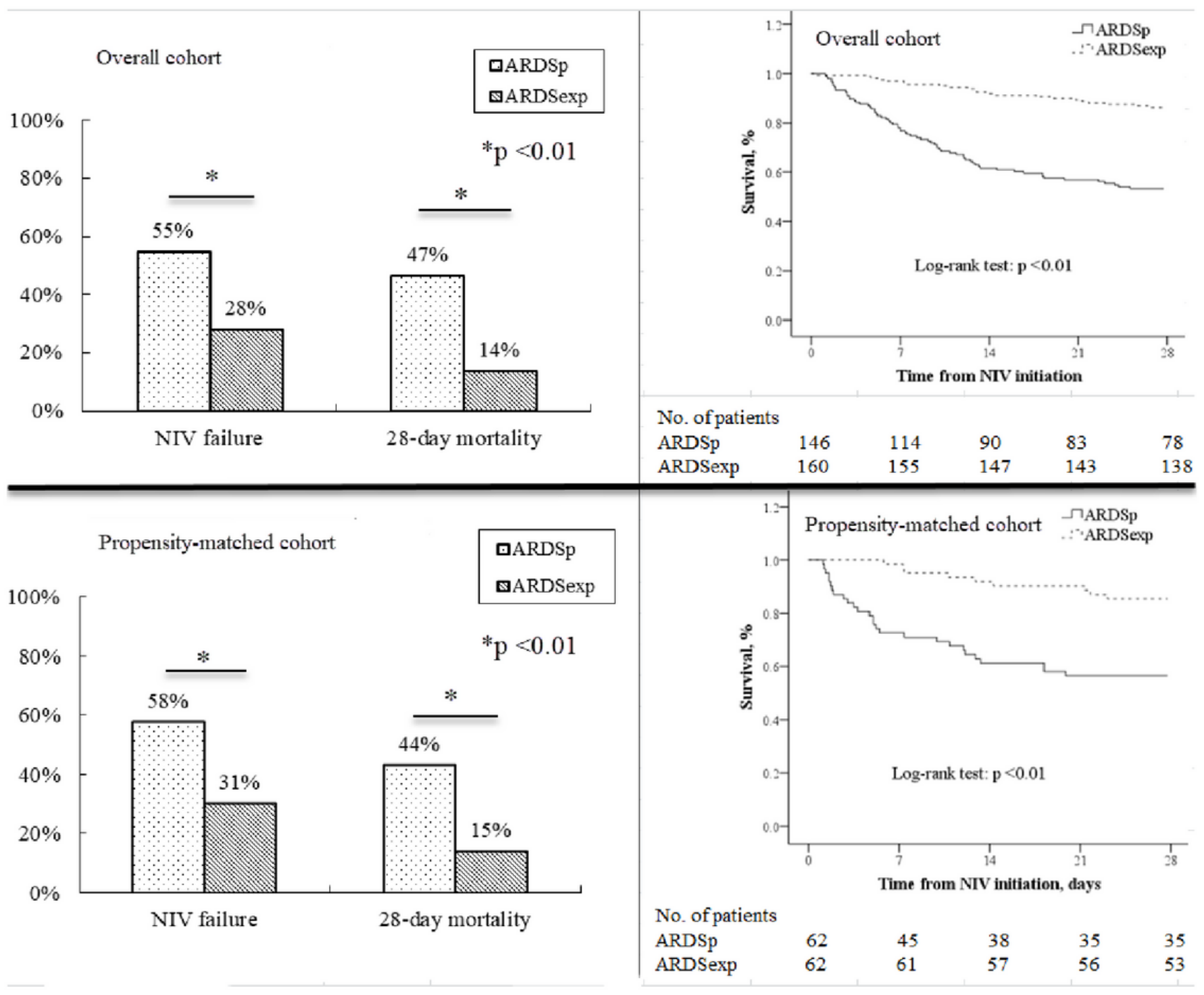

Figure 3

NIV failure and 28-day mortality in ARDS patients with pulmonary ARDS (ARDSp) and extrapulmonary ARDS (ARDSexp) 
A Risk for NIV failure (ARDSp vs. ARDSexp)

Confirmed ARDS after $24 \mathrm{~h}(\mathrm{n}=178)$

De novo acute respiratory failure $(n=275)$

Septic shock $(n=41)$

Without septic shock $(n=265)$

$\mathrm{PaO} 2 / \mathrm{FiO} 2<150 \mathrm{mmHg}$ before NIV $(\mathrm{n}=153)$

$\mathrm{PaO} 2 / \mathrm{FiO} 2 \geq 150 \mathrm{mmHg}$ before NIV $(\mathrm{n}=153)$

Without Pancreatitis $(n=206)$

Male $(\mathbf{n}=190)$

Female $(\mathrm{n}=116)$

Age $<65$ years $(\mathrm{n}=225)$

Age $\geq 65$ years $(n=81)$

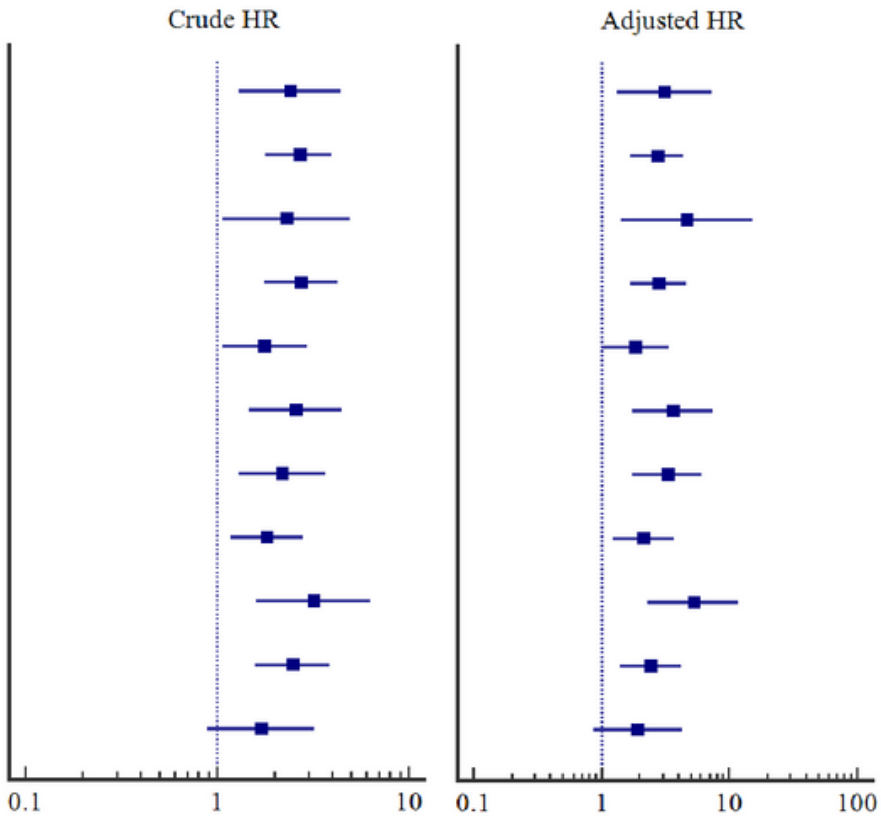

\section{B Risk for 28-day mortality (ARDSp vs. ARDSexp)}

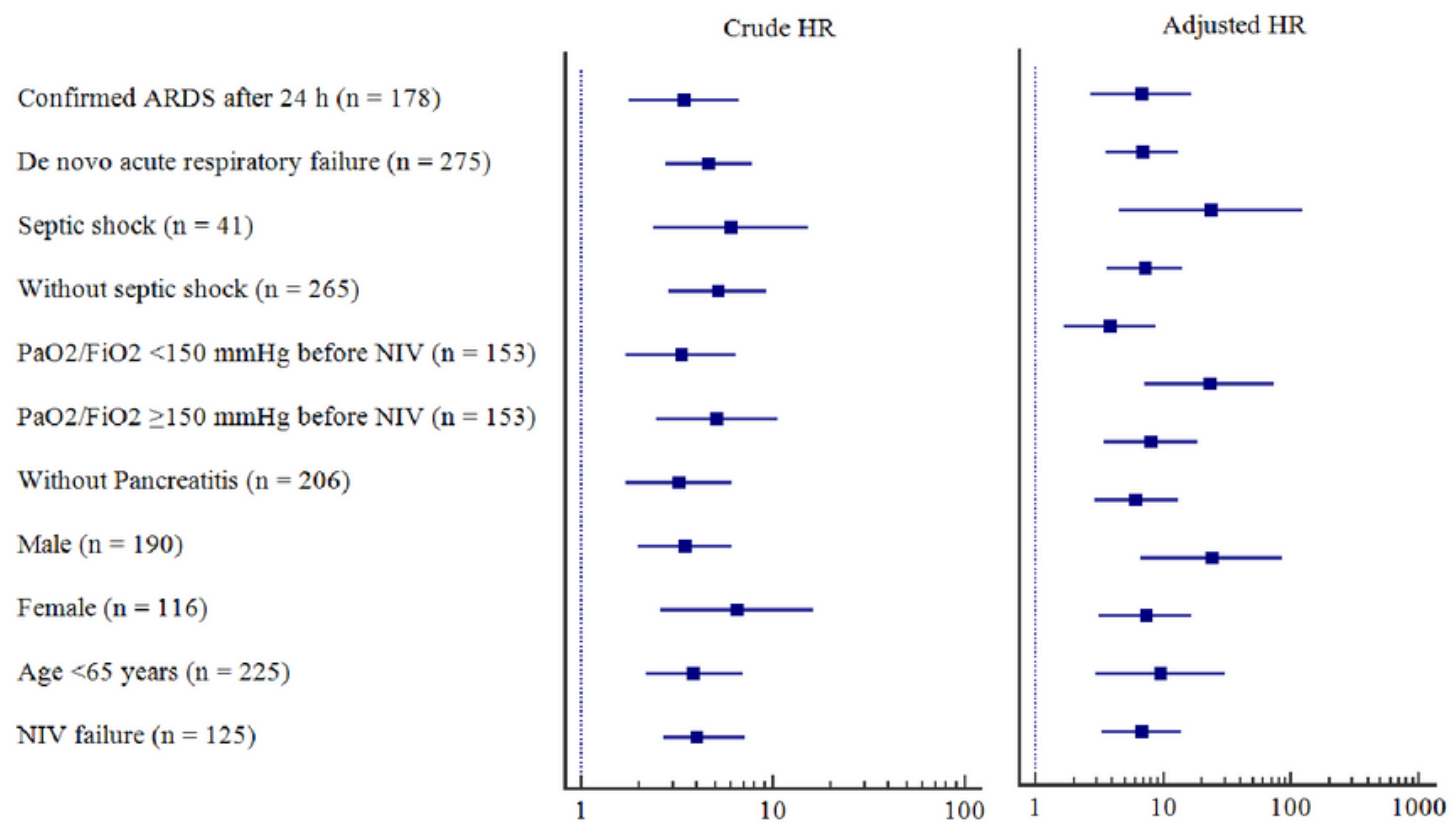

\section{Figure 4}

Sensitivity analysis in patients with different conditions The model was adjusted by sex, age, septic shock, chronic heart disease, chronic pulmonary disease, non-pulmonary SOFA score, ARDS severity, respiratory rate before NIV, heart rate before NIV, arterial blood gas tests before NIV, tidal volume at 1-2 $\mathrm{h}$ of NIV, and PEEP at 1-2 $\mathrm{h}$ of NIV. 